\title{
An updated meta-analysis of MitraClip versus surgery for mitral regurgitation
}

\author{
Nicholas A. $\mathrm{Oh}^{1,2}$, Polydoros N. Kampaktsis ${ }^{3}$, Michele Gallo ${ }^{4}$, Alvise Guariento ${ }^{5}$, Viktoria Weixler ${ }^{6}$, \\ Steven J. Staffa ${ }^{7}$, Dimitrios V. Avgerinos ${ }^{8}$, Andrea Colli ${ }^{9}$, Ilias P. Doulamis ${ }^{1}$
}

${ }^{1}$ Department of Cardiac Surgery, Boston Children's Hospital, Harvard Medical School, Boston, MA, USA; ${ }^{2}$ Department of Cardiothoracic Surgery, Cleveland Clinic Foundation, Cleveland, OH, USA; ${ }^{3}$ Division of Cardiology, Columbia University, Irving Medical Center, New York City, NY, USA; ${ }^{4}$ Department of Cardiac Surgery, Cardiocentro Ticino, Lugano, Switzerland; ${ }^{5}$ Division of Cardiovascular Surgery, The Labatt Family Heart Centre, The Hospital for Sick Children, Toronto, Ontario, Canada; ${ }^{6}$ Department of Cardiac Surgery, German Heart Institute, Berlin, Germany; ${ }^{7}$ Department of Anesthesiology, Critical Care and Pain Medicine Research, Boston Children's Hospital, Harvard Medical School, Boston, MA, USA; ${ }^{8}$ Department of Cardiothoracic Surgery, New York Presbyterian Hospital, Weill Cornell Medicine, New York City, NY, USA; ${ }^{9}$ Department of Surgical, Medical and Molecular Pathology and Critical Care Medicine, University of Pisa, Pisa, Italy

Correspondence to: Ilias P. Doulamis, MD, PhD. Department of Cardiac Surgery, Boston Children's Hospital, Harvard Medical School, 300 Longwood Ave, Boston, MA 02115, USA. Email: doulamis.i@gmail.com.

Background: Although studies demonstrate its feasibility, there is ongoing debate on the short and longterm outcomes of MitraClip versus surgical repair or mitral valve replacement (MVR). The objective of this meta-analysis is to compare the safety, morbidity, mortality and long-term function following MitraClip compared to MVR.

Methods: Articles were searched in PubMed and Cochrane databases for studies comparing outcomes of MitraClip and surgery on December 1, 2019. Eligible prospective, retrospective, randomized and nonrandomized studies were reviewed.

Results: A total of nine studies ( $\mathrm{n}=1,873$, MitraClip $=533, \mathrm{MVR}=644)$ were eligible for review. At baseline, MitraClip patients had more comorbidities than MVR patients, including myocardial infarction $(\mathrm{P}<0.001)$, chronic obstructive pulmonary disease $(\mathrm{P}=0.022)$ and chronic kidney disease $(\mathrm{P}<0.001)$. MitraClip was associated with shorter length of stay $(-3.86$ days; $95 \% \mathrm{CI},-4.73$ to $-2.99 ; \mathrm{P}<0.01)$ with a similar safety profile. Residual moderate-to-severe mitral regurgitation was more frequent in MitraClip at discharge (OR, 2.81; 95\% CI, 1.39-5.69; $\mathrm{P}<0.01)$ and at five years (OR, 2.46; 95\% CI, 1.54-3.94; $\mathrm{P}<0.01$ ), and there was a higher need for reoperation on the MitraClip group at latest follow-up (OR, 5.28; 95\% CI, 3.43-8.11; $\mathrm{P}<0.01)$. The overall mortality was comparable between the two groups (HR, 2.06; 95\% CI, 0.98-4.29; $\mathrm{P}=0.06$ ) for a mean follow-up of 4.8 years.

Conclusions: Compared to surgery, MitraClip demonstrates a similar safety profile and shorter length of stay in high-risk patients, at the expense of increased residual mitral regurgitation and higher reoperation rate. Despite this, long term mortality appears comparable between the two techniques, suggesting that a patient-tailored approach will lead to optimal results.

Keywords: MitraClip; mitral valve (MV); mitral valve repair; mitral regurgitation (MR)

Submitted Jul 22, 2020. Accepted for publication Sep 21, 2020.

doi: 10.21037/acs-2020-mv-24

View this article at: http://dx.doi.org/10.21037/acs-2020-mv-24 


\section{Introduction}

Mitral regurgitation (MR) is considered the second most frequent valve disease, significantly increasing with age, with a prevalence of over $9 \%$ in patients $\geq 75$ years of age $(1,2)$. MR can be divided into primary or degenerative MR (dMR) when caused by abnormalities of the mitral valve leaflets or chordae, and secondary or functional MR (fMR) when caused by abnormalities of the papillary muscles, left ventricle (LV) or mitral valve annulus. Despite the constant improvement of surgical mitral valve (MV) repair/ replacement (MVR) techniques and their outcomes, older symptomatic patients with severe MR, reduced $L V$ function and significant comorbidities are considered inoperable or high-risk for surgery $(1,3)$.

In these patients, percutaneous intervention on the MV has been introduced as an alternative option. Since 2013, MitraClip (Abbott Laboratories Inc, Chicago, IL, USA) is the only such percutaneous device approved by the U.S. Food and Drug Administration (FDA) for use in patients with MR grade $\geq 3+$ and high-risk for MV surgery. This employs the Alfieri edge-to-edge (E-to-E) technique, which was first introduced in the early 1990s to approximate the free edges of the mitral leaflets correcting MR without producing stenosis $(4,5)$. Several clinical studies have demonstrated the feasibility of the MitraClip procedure in high-risk patients and subsequently in non-high-risk patients (6-8). Endovascular Valve Edge-to-Edge Repair Study II (EVEREST II) is the only randomized clinical trial (RCT) comparing these two treatment modalities. This study suggested no difference in mortality or moderate or higher MR at one and five years $(9,10)$. Currently, however, there is controversy regarding the short-term and long-term outcomes of MitraClip versus MVR for MR, particularly in the low- to intermediate-risk population. A recent propensity score-matched analysis showed improved one year but lower five year survival among low- to intermediate-risk MitraClip patients with $\mathrm{dMR}$ (11). This meta-analysis sought to compare the safety, early and late mortality, morbidity and long-term function of the MV following MitraClip compared to MVR for either $\mathrm{fMR}$ or $\mathrm{dMR}$.

\section{Methods}

\section{Search strategy and article selection}

This systematic review was conducted in accordance with the Preferred Reporting Items for Systematic Reviews and Meta-Analyses (PRISMA) guidelines and in line with the protocol agreed by all authors (Figure S1) (12). Eligible studies were identified by a query of PubMed and Cochrane bibliographic databases (last search: December 1, 2019). Two investigators (IPD and NO), working independently, executed the search using the following Medical Subject Heading (MeSH)-term algorithm: "(percutaneous OR transcutaneous OR transcatheter OR catheter-based OR endo-vascular OR trans-septal) AND ("mitral valve repair" OR "edge-to-edge technique" OR "Alfieri's technique" OR "double-orifice technique" OR "mitra clip" OR mitraclip)". In addition, all references of relevant reviews and eligible articles were hand-searched for potentially missed eligible studies following a snowball procedure. Eligible studies met the following PICOS criteria: (I) population: adult human patients with either fMR or dMR; (II) intervention: surgical repair or replacement of the MV; (III) comparative intervention: MitraClip; (IV) outcome: any outcome of the present meta-analysis (reported below); (V) study design: Prospective studies, retrospective studies and randomized control trials. Only original studies written in English were included.

\section{Data extraction}

Eligible studies were reviewed and data extracted, specifically for study design, study origin, study timeframe, score in Newcastle-Ottawa Quality Scale (NOS), type of MR (functional or degenerative), type of surgical intervention and number of patients included. Patient data were reviewed and the following demographic variables were collected: gender, age, diabetes mellitus (DM), previous cardiac surgery, previous myocardial infarction (MI), atrial fibrillation (AF), chronic kidney disease (CKD), chronic obstructive pulmonary disease (COPD), Society of Thoracic Surgeons (STS) score and logistic euroSCORE. Data on post-operative acute kidney injury (AKI), stroke and length-of-stay were analyzed. Outcomes consisted of 30-day, one year and five year mortality, $M R \geq$ moderate at discharge and five years as well as re-operation on MV at latest follow-up.

\section{Statistical analysis}

All data extracted from eligible studies were tabulated and the outcomes were analyzed cumulatively. A descriptive approach was adopted in all parameters when a metaanalysis was not possible. Whenever the data were sufficient (i.e., at least two studies providing relevant data), a meta- 
analysis was performed. Between-studies comparisons for categorical variables were performed using the Pearson's Chi square test. Odds ratios (OR) and $95 \%$ confidence intervals (CI) were calculated by means of $2 \times 2$ tables for each categorical outcome, with OR greater than one denoting an outcome more frequently present in the MitraClip group. Mean difference with its corresponding $95 \%$ CI were calculated for length of stay, with values greater than zero corresponding to larger values in the MitraClip group. For a study without an available hazard ratio (HR), a HR was calculated from a Kaplan-Meier curve or summary data using the methods denoted by Parmar et al. and Williamson et al. $(13,14)$. Between-study heterogeneity was assessed through Cochran Q statistic and by estimating $\mathrm{I}^{2}$. Random-effects (DerSimonian-Laird) models were used to calculate pooled effect estimates for this meta-analysis. Meta-regression was utilized in the case of reoperation on MV due to the inconsistency of follow-up period among the studies. Only studies reporting the same follow-up period for MitraClip and Surgery groups were included and the effect of follow-up period as a moderator of the outcome was assessed. Moreover, meta-regression was used to assess the effect of comorbidities as moderators for primary outcomes. For the same outcomes, a predefined sensitivity analysis was performed removing one trial at a time (leave-one-out analysis).

\section{Assessment of study quality}

The quality of the included studies was evaluated using the Newcastle Ottawa Scale (NOS) (15). For the analysis, the cut-off follow-up period was set at 30 postoperative days and the adequacy of follow-up was set at a $90 \%$ rate. Evidently, items pertaining to the comparability of groups were marked as "not applicable" in the non-comparative studies. Two reviewers (MG and AG), working independently, rated the studies and final decision was reached by consensus with a third reviewer (NO). The Cochrane method was used to evaluate the methodological quality of each included trial (16). Each trial was judged to be of low, unclear or high risk of bias. Due to the nature of the interventions, none of the studies were blinded; we considered blinding not crucial for the outcome. The quality of the evidence (QoE) for each outcome was summarized with the GRADE (Grading of Recommendations Assessment, Development and Evaluation) method $(17,18)$. Publication bias using regression based Egger's test for small study effect was performed in the case of mortality, MR and MV re- operation outcomes. Statistical analysis was performed using Stata/SE version 16 (Stata Corp, College Station, TX, USA).

\section{Protocol registration}

Details of the protocol for this systematic review were registered on PROSPERO (ID180248, ongoing evaluation). This study had no funding and authors did not have any conflicts of interest.

\section{Results}

\section{Study characteristics and patient demographics}

The trial flow chart is shown in Figure 1. The initial literature search generated 1,562 studies. These studies were narrowed down based on the criteria above, and a total of 9 studies were determined eligible for this metaanalysis $(9,11,19-25)$. These studies were published between 2012 and 2019, and patient enrollment started in 1999. The majority of studies were retrospective, while one study was labeled as a prospective cohort study and one as a RCT (9). Evaluation of the included studies, in compliance with NOS, was performed and exhibited an average of 5.4/8 stars (Table S1). A total of 1,873 patients were included in our analysis (Table 1). Of these, 876 underwent MVR and 997 underwent MitraClip intervention. Male gender represented the majority of the population, ranging from $44 \%$ to $71 \%$. Mean age ranged between 62.6 and 82.0 years. Functional characteristics and comorbidities were also recorded (Tables 1,2). In our study, 504 patients had dMR and 273 patients had fMR. Almost all patients had a MR grade of $3+/ 4+$, with similar left ventricular ejection fraction of around $47 \%$. Compared to MVR, MitraClip patients had more comorbidities, such as prior MI $(25 \% \mathrm{vs}$. $36 \%$; $\mathrm{P}<0.001)$, AF ( $31 \%$ vs. $42 \%$; $\mathrm{P}<0.001)$, COPD (16\% vs. $24 \% ; \mathrm{P}=0.022)$ and $\mathrm{CKD}(12 \%$ vs. $33 \% ; \mathrm{P}<0.001)$, to highlight a few. Parallel to that, MitraClip patients had a higher calculated logistic EuroSCORE compared to patients that underwent MVR (12.2 vs. 18.5; $\mathrm{P}=0.01)$ (Table 1).

\section{Quality of evidence and publication bias}

All eligible studies were judged to be at unclear risk of bias (Figure S2). We did not receive any additional data from corresponding authors. Egger's test revealed that there was significant publication bias only in the case of five year mortality $(b=-29.5$; Standard Error, 5.95; $\mathrm{P}<0.001)$ 

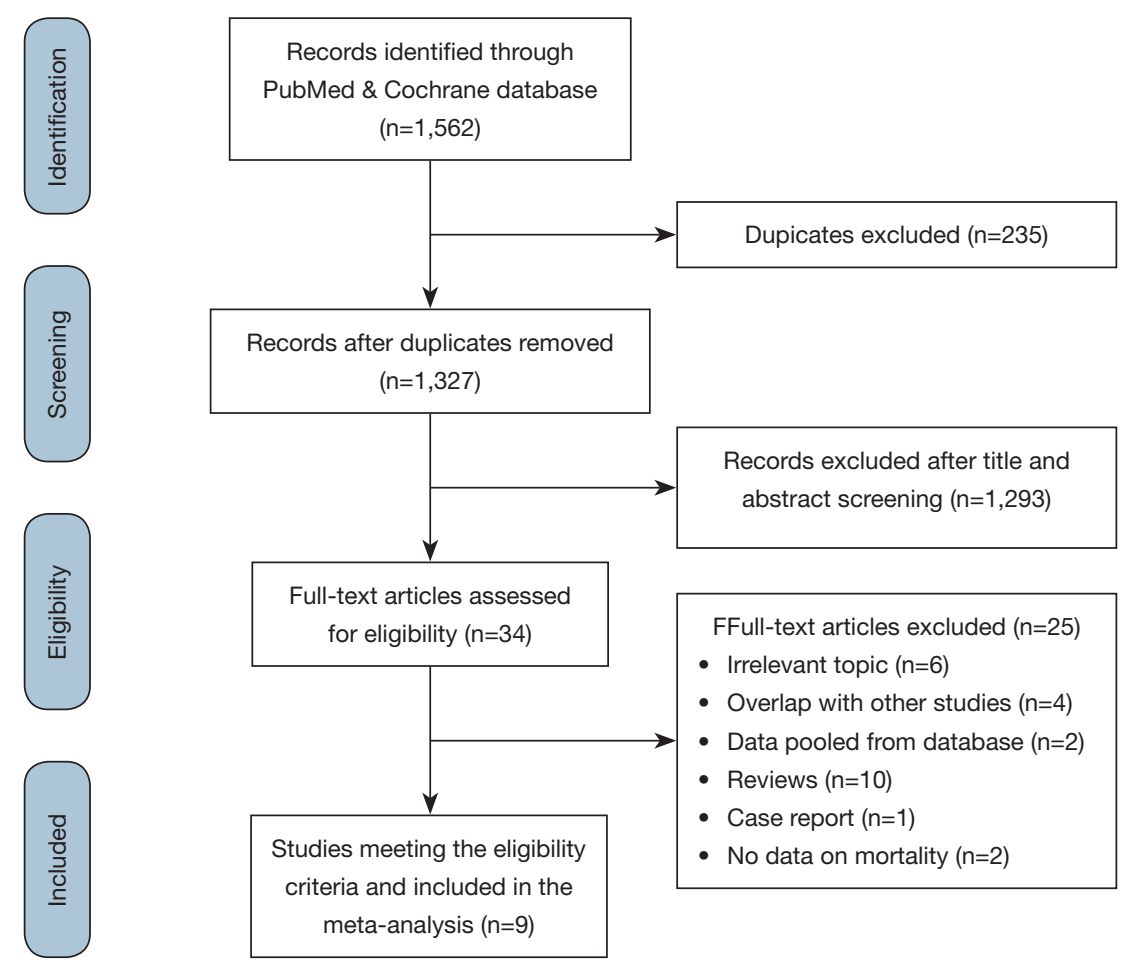

Figure 1 Flow diagram according to Preferred Reporting Items for Systemic Review and Meta-Analyses guidelines. N, number of studies.

(Figure S3).

\section{Short term mortality and complications}

After review of length-of-stay data from 533 MitraClip and 644 MVR patients, our study found that MitraClip was associated with a shorter length-of-stay (Mean Difference, -3.86 days; $95 \% \mathrm{CI},-4.73$ to $-2.99 ; \mathrm{P}<0.01$ ) (Figure $2 A$ ). Thirty-day mortality was found to be similar between MitraClip (1.54\%) and MVR (1.42\%) (OR, 1.04; 95\% CI, 0.58-1.88; $\mathrm{P}=0.88$ ) (Figure 2B). Compiled data from postprocedural in-hospital complications, specifically AKI and neurologic injury, were also reviewed and analyzed. Our study found no significant difference between MitraClip and MVR in terms of AKI events (OR, 0.82; 95\% CI, 0.35-1.92; $\mathrm{P}=0.65$ ) (Figure $2 C$ ) and incidence of post-operative stroke or neurologic complications (OR, 0.68; 95\% CI, 0.34-1.37; $\mathrm{P}=0.28$ ) (Figure 2D).

\section{Mortality and mitral valve regurgitation at 1 and 5 years \\ Comparison of one year mortality in patients with}

MitraClip (15.6\%) and MVR (12.0\%) demonstrated increased risk for MitraClip (OR, 1.48; 95\% CI, 1.03-2.16; $\mathrm{P}=0.04$ ) (Figure $3 A$ ). At the five year mark, the results suggested no difference in mortality between MitraClip (54.7\%) and MVR (50.4\%) (OR, 1.44; 95\% CI, 0.56-3.70; $\mathrm{P}=0.44)$ (Figure 3B). Given the increased comorbidity burden of the MitraClip patients, we performed a metaanalysis that included only studies that reported adjusted HRs for mortality and studies that used randomized patient recruitment or propensity-match scoring analysis. MitraClip was associated with a non-significant increase in overall mortality (HR, 2.06; 95\% CI, 0.98-4.29; $\mathrm{P}=0.06$ ) for a mean follow-up of 4.8 years (Figure 3C).

We also reviewed the incidence of residual moderateto-severe MR as demonstrated by echocardiography. Our analysis found more frequent recurrent or persistent 3+/4+ MR after MitraClip vs. MVR at discharge (OR, 2.81; 95\% CI, 1.39-5.69; $\mathrm{P}<0.01$ ) (Figure 4A). In addition, MitraClip continued to have more frequent moderate-to-severe MR at five years compared to MVR (OR; 2.46; 95\% CI, 1.54-3.94; $\mathrm{P}<0.01$ ) (Figure $4 B$ ). Also, there was a higher need for reoperation on the MV in the MitraClip group 


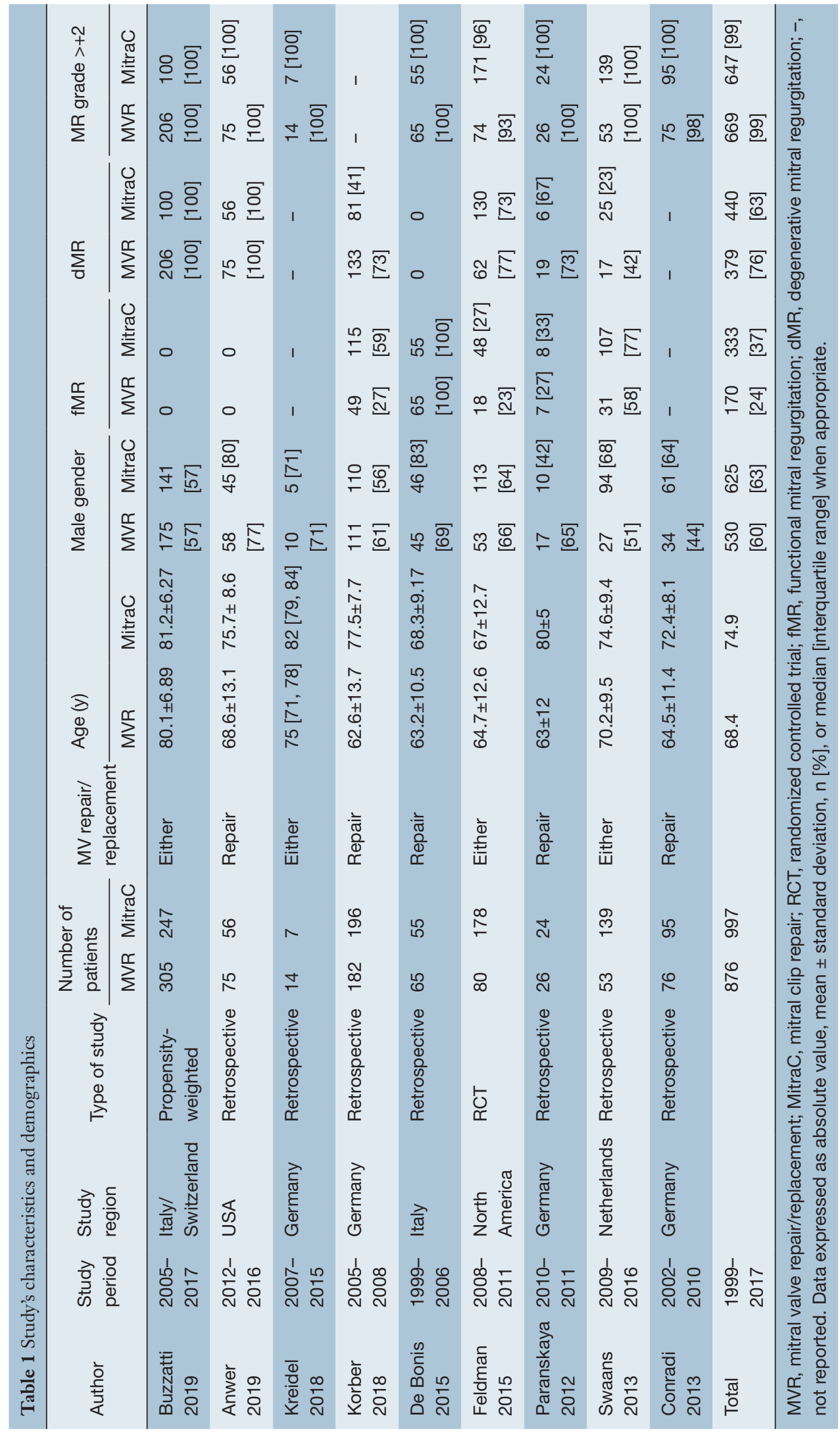




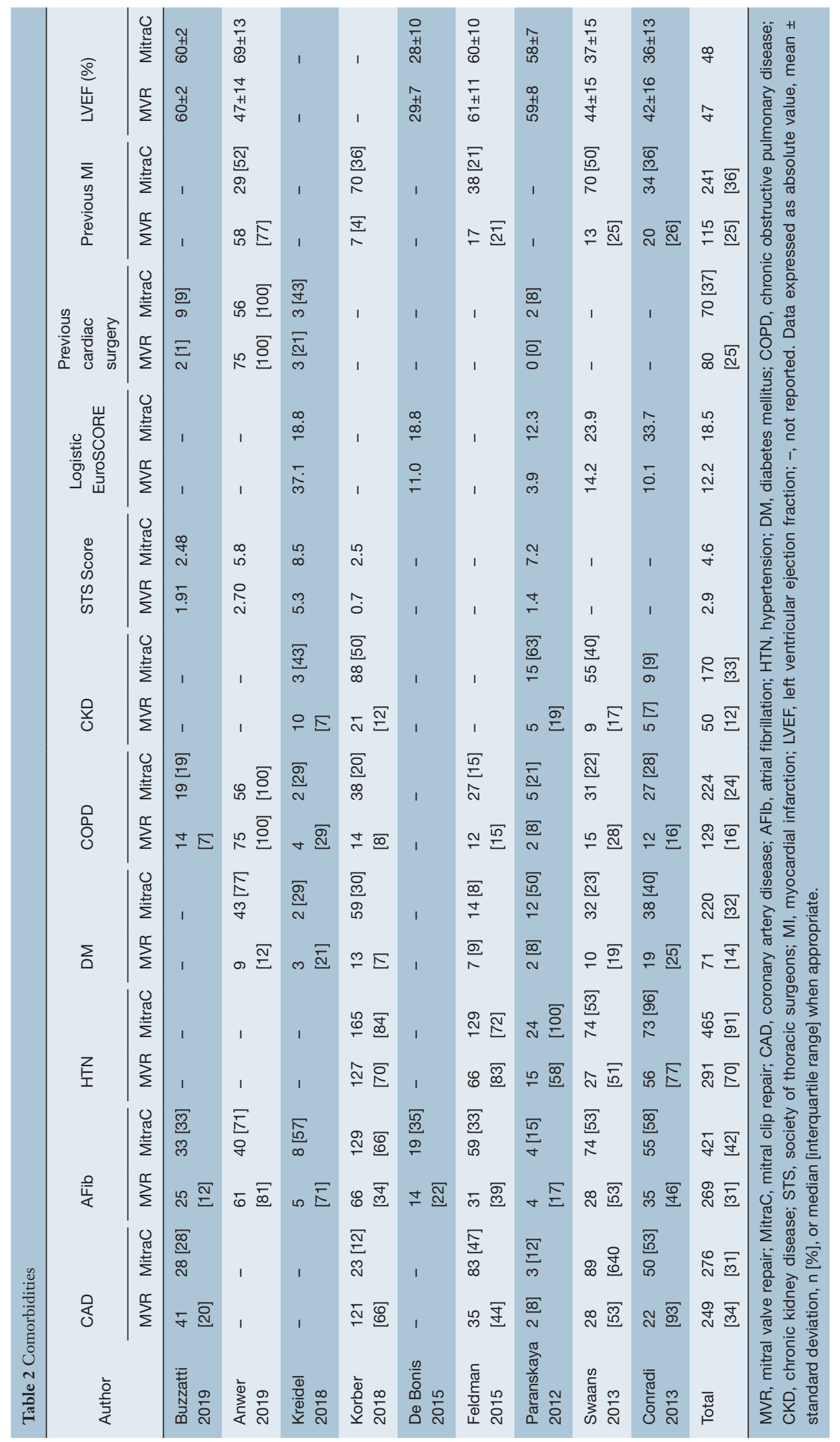




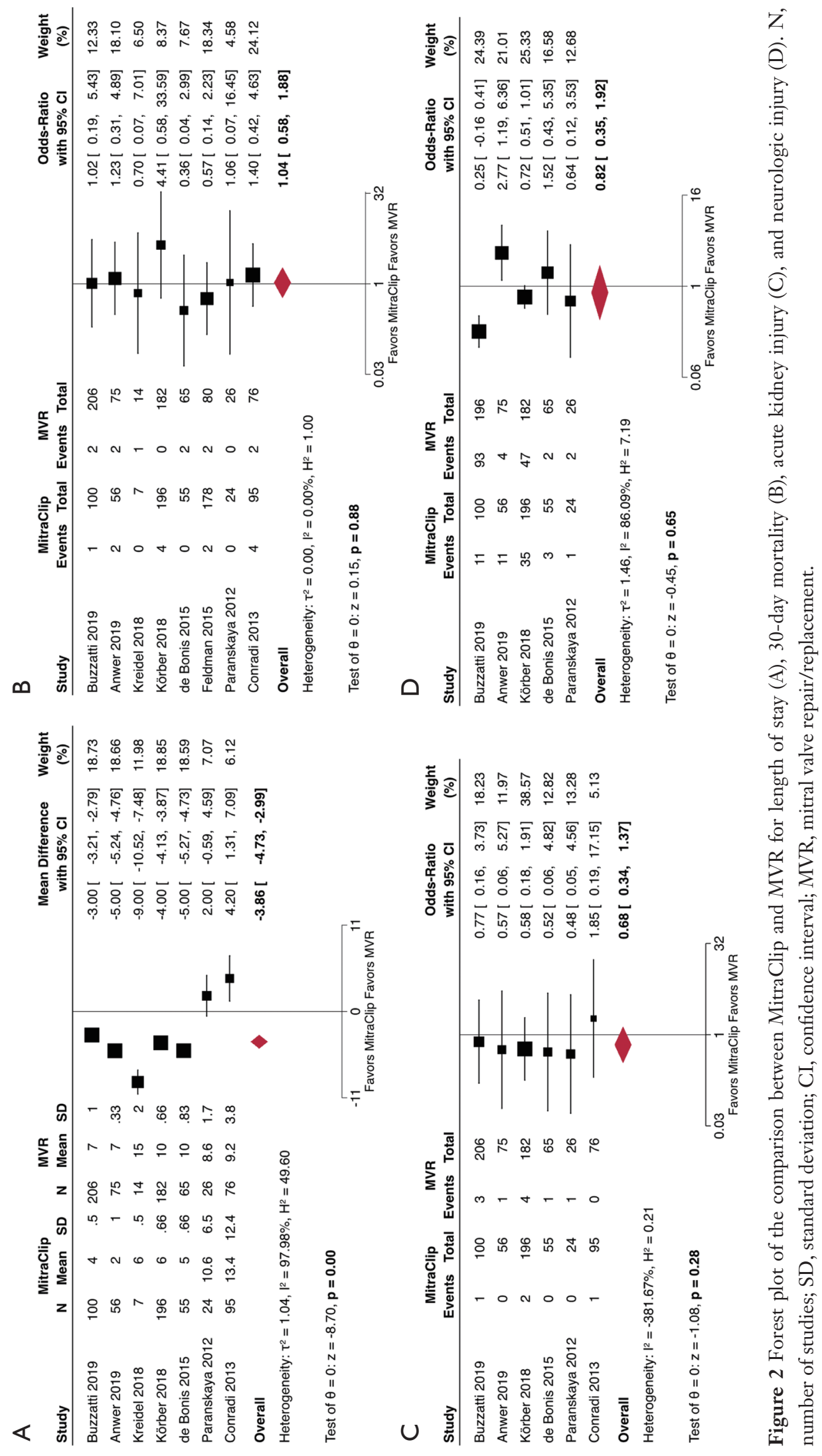




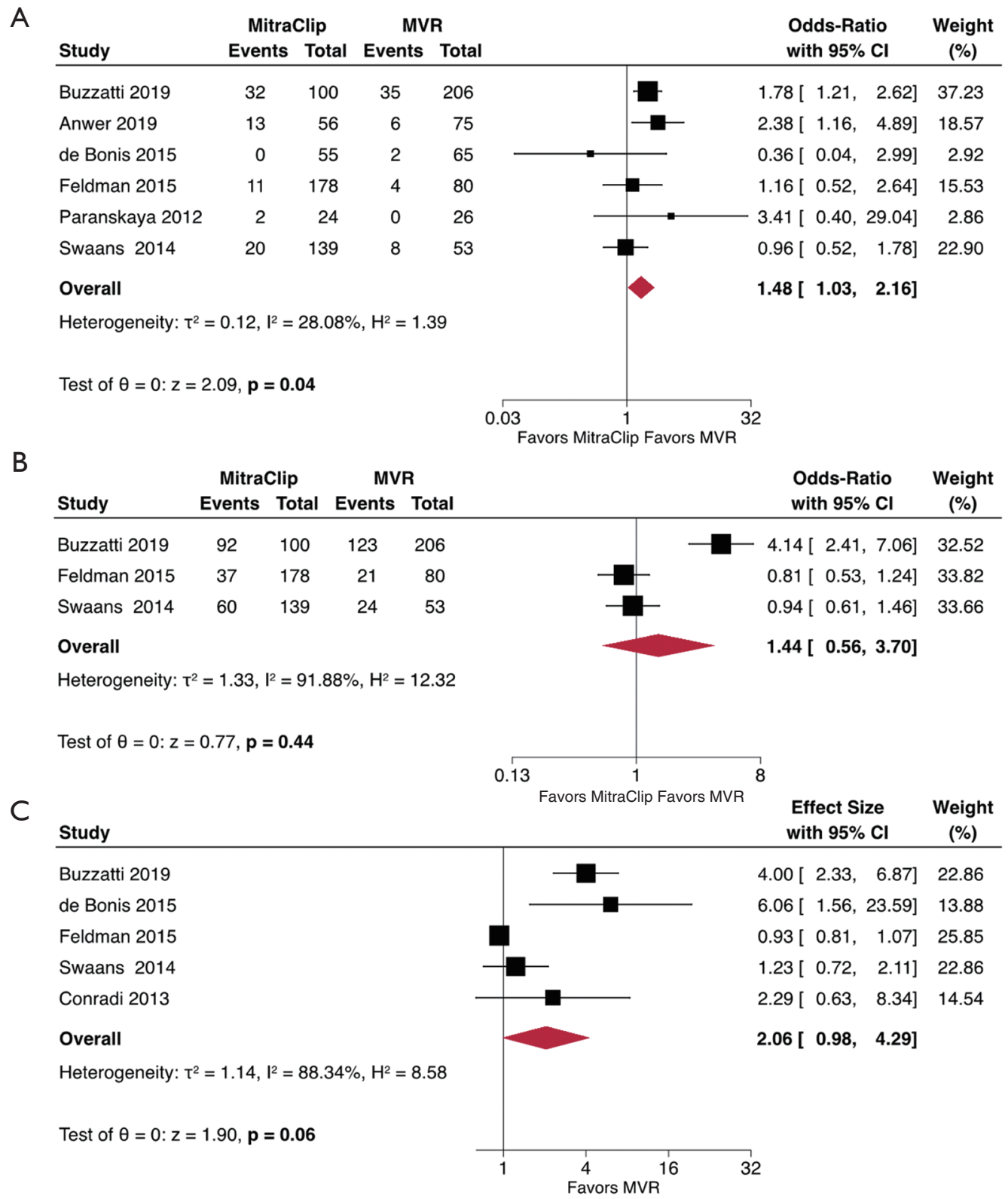

Figure 3 Forest plot of the comparison between MitraClip and MVR for 1-year mortality (A), 5-year mortality (B), and adjusted mortality (C). MVR, mitral valve repair/replacement; CI, confidence interval.

at latest follow-up (OR, 5.28; 95\% CI, 3.43-8.11; $\mathrm{P}<0.01)$ (Figure $4 C$ ). Meta-regression showed that the different follow-up periods among studies was not a significant moderator for this outcome (Coefficient, 0.004; 95\% CI, -0.028-0.037; $\mathrm{P}=0.797)$. A sub-group analysis stratified by type of MR (dMR or $\mathrm{fMR}$ ) was deferred to the small number of studies providing that information (maximum of two studies per outcome).

\section{Outcomes and moderators}

Meta-regression of age, male gender, EuroSCORE, STS score, AF, DM, COPD, CKD and hypertension were identified as potential moderators of MR, mortality and reoperation on the $\mathrm{MV}$ identified age and male gender as moderators for 5 -year mortality (Coefficient, -0.16 ; $95 \%$ CI, -0.32 to $-0.01 ; \mathrm{P}=0.038$ and Coefficient, $30.87 ; 95 \%$ CI, 18.64-43.11; $\mathrm{P}<0.001$, respectively) (Table S2). 


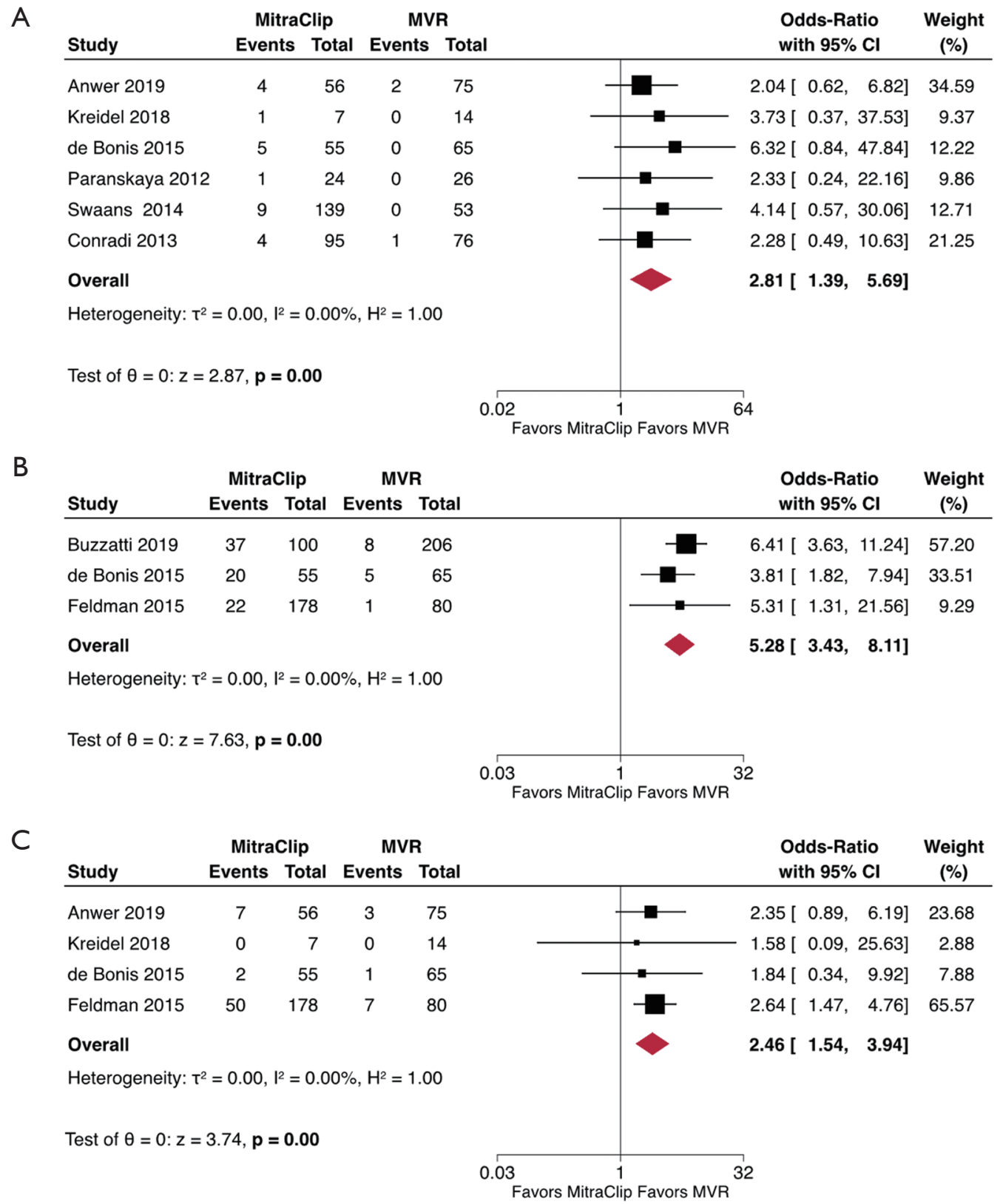

Figure 4 Forest plot of the comparison between MitraClip and MVR for mitral regurgitation at discharge (A), mitral regurgitation at 5 years (B), and mitral valve re-operations at follow-up (C). MVR, mitral valve repair/replacement; CI, confidence interval.

\section{Sensitivity analysis}

The results remained consistent at most predefined sensitivity analyses (Figure 5). The removal of the study by Buzzatti et al. (highest weight) at leave-one-out analysis showed no change in 30-day mortality, $M R>2+$ and mortality at five years, but revealed that there was no difference in mortality at one year (OR: 1.52; $95 \%$ CI, $0.72-3.22 ; \mathrm{P}=0.28)$. The removal of the study by Anwer et al. (highest weight) showed no change in $\mathrm{MR}>2+$ at discharge. The removal of the EVEREST II trial (highest weight) revealed that MitraClip was not associated with higher MV reoperation rate at follow-up (OR, 3.02; 95\% 

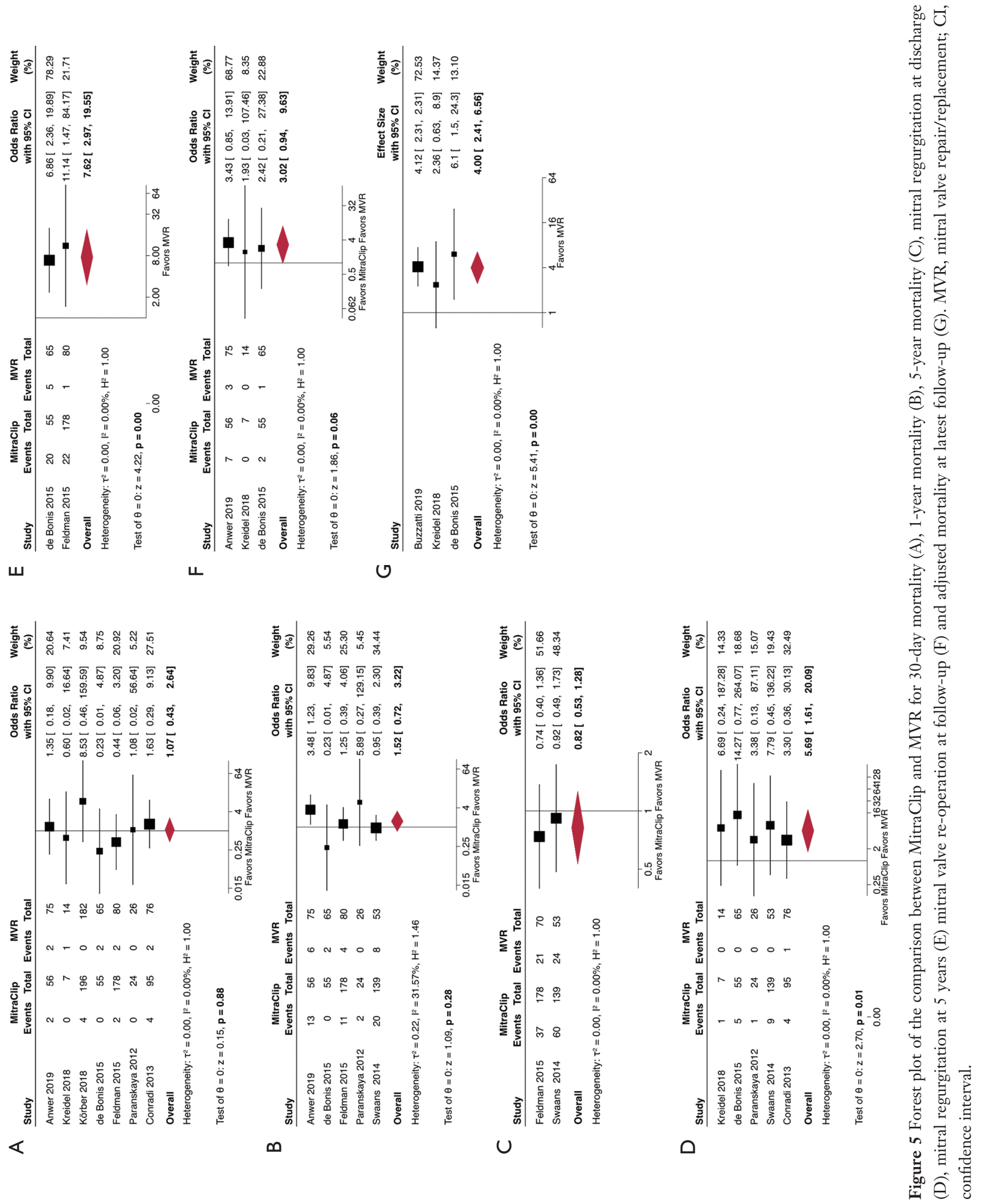
CI, 0.94-9.63; $\mathrm{P}=0.06$ ) (Figure 5). The removal of the EVEREST II trial (highest weight) revealed that MitraClip was associated with an increased risk for adjusted mortality at latest follow-up (HR, 4.0; 95\% CI, 2.41-6.56; $\mathrm{P}<0.01)$ (Figure 5).

Sub-group analysis of the studies including only patients who underwent MitraClip vs. MV repair showed a higher rate for moderate/severe MR at discharge (OR, 2.55; 95\% $\mathrm{CI}, 1.15-5.69 ; \mathrm{P}=0.02)$ and at one year post-operatively (OR, 3.18 ; 95\% CI, 1.32-7.62; $\mathrm{P}=0.01$ ) (Figure S4).

\section{Discussion}

MVR is the recommended intervention for $\mathrm{dMR}$ and has a role in $\mathrm{fMR}$ for patients who are surgical candidates $(26,27)$. A less invasive percutaneous procedure using MitraClip has recently been developed for patients who are at a prohibitive or high risk for surgery, or for those who prefer a minimally invasive option $(1,3,28)$. Selecting the appropriate patient who will benefit from MitraClip is of paramount importance. According to the results of the Percutaneous Repair with the MitraClip Device for Severe Functional/Secondary Mitral Regurgitation (MITRAFR) and the Cardiovascular Outcomes Assessment of the MitraClip Percutaneous Therapy for Heart Failure Patients with Functional Mitral Regurgitation (COAPT) trials, MitraClip reduces heart failure hospitalization and mortality, particularly in patients with moderate-to-severe $\mathrm{fMR}$, defined as effective regurgitant orifice area $\geq 30 \mathrm{~mm}^{2}$, LV ejection fraction between $20-50 \%, L V$ end-systolic diameter $<70 \mathrm{~mm}$ and/or regurgitant volume $>45 \mathrm{~mL}$ (29-31). This meta-analysis was conducted in order to obtain key insights on the long-term outcomes of MitraClip vs. MVR from a pooled population of patients with $M R$, specifically regarding long-term mortality and MR recurrence. Our key findings suggest that MitraClip has comparable short- and long-term outcomes to that of MVR for high-risk patients, despite the higher residual burden of $M R$ and the increased frequency of comorbidities in these patients. This is consistent with the one-year and five-year results of the EVEREST II Trial $(9,10)$.

With regard to peri-procedural outcomes, our results show a similar safety profile of MitraClip and MVR, with no difference in 30-day mortality, renal failure or neurologic complications. Moreover, length of stay is significantly lower with MitraClip vs. MVR. Given the increased burden of comorbidities in the majority of the
MitraClip population, this reflects the feasibility and safety of the procedure, which has been shown in large registries after its approval. On the other hand, our results confirm the higher frequency of residual $3+/ 4+M R$ at discharge compared to MVR. This is in accordance with the early experience from the EVEREST II Trial, where MitraClip procedural success was relatively low. With increasing experience though, procedural success is now reported at rates $>90 \%$ for MitraClip (32).

Unadjusted one year mortality appeared to be improved in MVR vs. MitraClip in our meta-analysis $(\mathrm{P}=0.04)$. However, when performing an analysis of adjusted HRs for a mean follow-up period of 4.8 years, the difference in mortality is no longer significant, although there is still a trend favoring MVR ( $\mathrm{P}=0.06)$. This finding may be due to either the smaller sample size or the adjustment of covariates that are different between the two populations. Sensitivity analysis showed a survival benefit for MVR, highlighting possible bias of the included studies. Five year mortality also appeared equivalent between the two procedures. These findings parallel the results of the EVEREST II Trial (9). Although our analysis included the study by Buzzatti et al., which demonstrated improved one year but worse five year survival after MitraClip vs. MVR in low-intermediate risk elderly patients with $\mathrm{dMR}$, we note that there is a current lack of similar studies (11). Additionally, when leave-oneout sensitivity analysis was performed, results remained unchanged. For these reasons, the results of this analysis should be cautiously interpreted and extrapolated to the general population and no conclusions can be reached regarding recommendations for MitraClip.

Despite the increasing experience with MitraClip reflected in the smaller number of re-operations after MitraClip (one year re-operation rate $21 \%$ in the EVEREST II Trial vs. $11 \%$ in the study by Anwer et al.), our results confirmed the significantly increased risk of reoperation after MitraClip (19). This is not surprising given our findings of significantly increased residual/recurrent MR at discharge and at five years. While the EVEREST II Trial showed that mortality up to five years after the index procedure was not affected by the inherently imperfect nature of the MitraClip procedure compared to the durable results of MVR, this applies to high risk patients only (9). Even with our thorough analysis, definitive conclusions cannot be made at this point regarding the long-term durability, safety and survival of low-intermediate risk MitraClip patients compared to MVR patients. MVR 
should still be considered the gold standard treatment of these patients particularly for dMR until further RCTs addressed the issue.

The selection of the procedure for each patient was based on clinical and anatomical complexity, surgical skills, transcatheter and echocardiographic skills and experience, personal confidence of the procedure and personal conflict of interest. This highlights that the determination of the optimal management is the result of the collaboration of the heart team, which focuses on optimizing treatment on a single-patient level rather than coming up with the old concept that one operation fits all.

\section{Limitations}

An intrinsic limitation of our study is the significantly different comorbidity burden among the non-randomized patients who receive MVR vs. MitraClip, which is reflected in a higher STS score in the latter. This results from that fact that MitraClip is currently indicated for patients who are at high risk for surgery. However, a separate meta-analysis using adjusted HRs was performed to address this difficulty, which showed no difference in long-term mortality when comparing the two interventions. Our meta-regression additionally showed no effect of comorbidity variation on the outcomes. Moreover, the outcomes of MVR $v s$. MitraClip stratified by MR could not be analyzed in this study due to the scarcity of studies including solely dMR or fMR. Surgical patients were treated with both MV replacement and repair, thus potentially impairing the final conclusion that technically feasible repair is superior to replacement in all $\mathrm{dMR}$ patients and preferable in $\mathrm{fMR}$ patients too if LV is not excessively enlarged. Considering that seven out of nine studies included in the analysis were retrospective, we could also argue that current results could potentially suffer from the original selection bias of choosing one procedure over the other. In other words, this analysis could highlight that a patient-tailored approach in selecting the MV procedure improved survival in a heterogeneous high-risk population. Finally, due to the limited number of eligible studies, data on reoperation and cardiac-specific mortality could not be analyzed.

In conclusion, our analyses of compiled data from nine studies suggest that MitraClip provides a shorter length of stay with a safety profile similar to MVR in high risk patients, at the expense of higher rates of recurrent/residual MR and increased risk of reoperations. However, long-term mortality appears equivalent between the two techniques, showing that a patient-tailored approach is mandatory to improve results. Our results should be interpreted with caution as MitraClip patients currently have a larger comorbidity burden at baseline. Although these findings are encouraging, expansion of MitraClip in low-intermediate risk patients with $\mathrm{dMR}$ requires further RCTs to address its durability and long-term outcomes in this population.

\section{Acknowledgments}

Funding: None.

\section{Footnote}

Conflicts of Interest: The authors have no conflicts of interest to declare.

Open Access Statement: This is an Open Access article distributed in accordance with the Creative Commons Attribution-NonCommercial-NoDerivs 4.0 International License (CC BY-NC-ND 4.0), which permits the noncommercial replication and distribution of the article with the strict proviso that no changes or edits are made and the original work is properly cited (including links to both the formal publication through the relevant DOI and the license). See: https://creativecommons.org/licenses/by-nc-nd/4.0/.

\section{References}

1. Mirabel M, Iung B, Baron G, et al. What are the characteristics of patients with severe, symptomatic, mitral regurgitation who are denied surgery? Eur Heart J 2007;28:1358-65.

2. Singh JP, Evans JC, Levy D, et al. Prevalence and clinical determinants of mitral, tricuspid, and aortic regurgitation (The Framingham Heart Study). Am J Cardiol 1999;83:897-902.

3. Detaint D, Sundt TM, Nkomo VT, et al. Surgical correction of mitral regurgitation in the elderly: Outcomes and recent improvements. Circulation 2006;114:265-72.

4. Alfieri O, Denti P. Alfieri stitch and its impact on mitral clip. Eur J Cardiothorac Surg 2011;39:807-8.

5. Maisano F, Schreuder JJ, Oppizzi M, et al. The doubleorifice technique as a standardized approach to treat mitral regurgitation due to severe myxomatous disease: Surgical technique. Eur J Cardiothorac Surg 2000;17:201-5.

6. Kar S, Feldman T, Qasim A, et al. Five-year outcomes of transcatheter reduction of significant mitral regurgitation 
in high-surgical-risk patients. Heart 2019;105:1622-8.

7. Ansari MT, Ahmadzai N, Coyle K, et al. Mitral valve clip for treatment of mitral regurgitation: An evidence-based analysis. Ont Health Technol Assess Ser 2015;15:1-104.

8. Taramasso M, Maisano F, Latib A, et al. Clinical outcomes of MitraClip for the treatment of functional mitral regurgitation. EuroIntervention 2014;10:746-52.

9. Feldman T, Kar S, Elmariah S, et al. Randomized Comparison of Percutaneous Repair and Surgery for Mitral Regurgitation 5-Year Results of EVEREST II. J Am Coll Cardiol 2015;66:2844-54.

10. Feldman T, Foster E, Glower DD, et al. Percutaneous repair or surgery for mitral regurgitation. $\mathrm{N}$ Engl J Med 2011;365:1395-406.

11. Buzzatti N, Van Hemelrijck M, Denti P, et al. Transcatheter or surgical repair for degenerative mitral regurgitation in elderly patients: A propensity-weighted analysis. J Thorac Cardiovasc Surg 2019;158:86-94.e1.

12. Liberati A, Altman DG, Tetzlaff J, et al. The PRISMA statement for reporting systematic reviews and metaanalyses of studies that evaluate healthcare interventions: explanation and elaboration. BMJ 2009;339:b2700.

13. Williamson PR, Smith CT, Hutton JL, et al. Aggregate data meta-analysis with time-to-event outcomes. Stat Med 2002;21:3337-51.

14. Parmar MK, Torri V, Stewart L. Extracting summary statistics to perform meta-analyses of the published literature for survival endpoints Stat Med 1998;17:2815-34.

15. Wells GA, Shea B, O'Connell D, et al. The NewcastleOttawa Scale (NOS) for assessing the quality of nonrandomised studies in meta-analyses. 2013. Vol. 113. Available online: http://www.ohri.ca/programs/clinical_ epidemiology/oxford.asp

16. Higgins JPT, Altman DG, Gøtzsche PC, et al. The Cochrane Collaboration's tool for assessing risk of bias in randomised trials. BMJ 2011;343:d5928.

17. Guyatt GH, Oxman AD, Vist GE, et al. GRADE: an emerging consensus on rating quality of evidence and strength of recommendations. BMJ 2008;336:924-6.

18. Guyatt G, Oxman AD, Akl EA, et al. GRADE guidelines: 1 . Introduction - GRADE evidence profiles and summary of findings tables. J Clin Epidemiol 2011;64:383-94.

19. Anwer LA, Dearani JA, Daly RC, et al. Degenerative Mitral Regurgitation After Nonmitral Cardiac Surgery: MitraClip Versus Surgical Reconstruction. Ann Thorac Surg 2019;107:725-31.

20. Conradi L, Treede H, Rudolph V, et al. Surgical or percutaneous mitral valve repair for secondary mitral regurgitation: Comparison of patient characteristics and clinical outcomes. Eur J Cardiothorac Surg 2013;44:490-6.

21. De Bonis M, Taramasso M, Lapenna E, et al. MitraClip therapy and surgical edge-to-edge repair in patients with severe left ventricular dysfunction and secondary mitral regurgitation: Mid-term results of a single-centre experience. Eur J Cardiothorac Surg 2016;49:255-62.

22. Körber MI, Silwedel J, Friedrichs K, et al. Bleeding Complications After Percutaneous Mitral Valve Repair With the MitraClip. Am J Cardiol 2018;121:94-9.

23. Kreidel F, Alessandrini H, Wohlmuth P, et al. Is Surgical or Catheter-based Interventions an Option After an Unsuccessful Mitral Clip? Semin Thorac Cardiovasc Surg 2018;30:152-7.

24. Paranskaya L, D’Ancona G, Bozdag-Turan I, et al. Percutaneous mitral valve repair with the MitraClip ${ }^{\circledR}$ system: Perioperative and 1-year follow-up results using standard or multiple clipping strategy. Catheter Cardiovasc Interv 2013;81:1224-31.

25. Swaans MJ, Bakker ALM, Alipour A, et al. Survival of transcatheter mitral valve repair compared with surgical and conservative treatment in high-surgical-risk patients. JACC Cardiovasc Interv 2014;7:875-81.

26. Nishimura RA, Otto CM, Bonow RO, et al. 2017 AHA/ ACC Focused Update of the 2014 AHA/ACC Guideline for the Management of Patients With Valvular Heart Disease: A Report of the American College of Cardiology/ American Heart Association Task Force on Clinical Practice Guidelines. Circulation 2017;135:e1159-95.

27. Nishimura RA, Otto CM, Bonow RO, et al. 2014 AHA/ ACC Guideline for the Management of Patients With Valvular Heart Disease: executive summary: a report of the American College of Cardiology/American Heart Association Task Force on Practice Guidelines. Circulation 2014;129:2440-92.

28. Condado JA, Acquatella H, Rodriguez L, et al. Percutaneous edge-to-edge mitral valve repair: 2-Year follow-up in the first human case. Catheter Cardiovasc Interv 2006;67:323-5.

29. Obadia JF, Messika-Zeitoun D, Leurent G, et al. Percutaneous repair or medical treatment for secondary mitral regurgitation. N Engl J Med 2018;379:2297-306.

30. Stone GW, Lindenfeld JA, Abraham WT, et al. Transcatheter mitral-valve repair in patients with heart failure. N Engl J Med 2018;379:2307-18. 
31. Pibarot P, Delgado V, Bax JJ. MITRA-FR vs. COAPT: lessons from two trials with diametrically opposed results. Eur Heart J Cardiovasc Imaging 2019;20:620-4.

32. Sorajja P, Vemulapalli S, Feldman T, et al. Outcomes

Cite this article as: Oh NA, Kampaktsis PN, Gallo M, Guariento A, Weixler V, Staffa SJ, Avgerinos DV, Colli A, Doulamis IP. An updated meta-analysis of MitraClip versus surgery for mitral regurgitation. Ann Cardiothorac Surg 2021;10(1):1-14. doi: 10.21037/acs-2020-mv-24
With Transcatheter Mitral Valve Repair in the United States: An STS/ACC TVT Registry Report. J Am Coll Cardiol 2017;70:2315-27. 
PRISMA 2009 Checklist

\begin{tabular}{|c|c|c|c|c|}
\hline Section/topic & $\begin{array}{l}\text { Item } \\
\text { No }\end{array}$ & Checklist item & \begin{tabular}{|l|}
$\begin{array}{l}\text { Reported on Page } \\
\text { Number/Line } \\
\text { Number }\end{array}$ \\
\end{tabular} & $\begin{array}{l}\text { Reported on } \\
\text { Section/Paragraph }\end{array}$ \\
\hline \multicolumn{5}{|l|}{ TITLE } \\
\hline Title & 1 & Identify the report as a systematic review, meta analysis, or both. & $1 / 1$ & \\
\hline \multicolumn{5}{|l|}{ ABSTRACT } \\
\hline $\begin{array}{l}\text { Structured } \\
\text { summary }\end{array}$ & 2 & 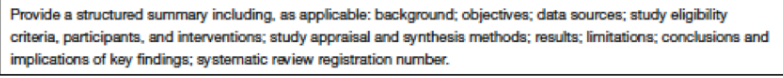 & 231.53 & \\
\hline \multicolumn{5}{|l|}{ INTRODUCTION } \\
\hline Rationale & 3 & Describe the rationale for the review in the context of what is already known. & $3 / 50-75$ & \\
\hline Objectives & 4 & \begin{tabular}{|l}
$\begin{array}{l}\text { Provide an explicit statementent of questions being addressed with referernce to participants, interventions, } \\
\text { comparisons, outcomes, and study dosign (PICOS). }\end{array}$ \\
\end{tabular} & $3 / 6-77$ & \\
\hline \multicolumn{5}{|l|}{ METHODS } \\
\hline $\begin{array}{l}\text { Protocol and } \\
\text { registration }\end{array}$ & 5 & $\begin{array}{l}\text { Indicate if a review protoool exists, if and where it can be accessed (e.g. Web address), and, if available, provide } \\
\text { registration information inchuding registration number. }\end{array}$ & 5/440-142 & \\
\hline Eligbility criteria & 6 & 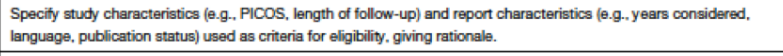 & 489.93 & \\
\hline $\begin{array}{l}\text { Information } \\
\text { sourcoss }\end{array}$ & 7 & $\begin{array}{l}\text { Describe all information sources (e.g. databases with dates of coverage, contact with study authors to identily } \\
\text { additional studies) in the search and date last searched. }\end{array}$ & $483-89$ & \\
\hline Search & 8 & $\begin{array}{l}\text { Presentr full elactronic search stratagy for at least one database, including any limits used, such that it could be } \\
\text { repeatted. }\end{array}$ & 48488 & \\
\hline Study selection & 9 & $\begin{array}{l}\text { Statt the process for selecting studies fie., screening, elligibility, included in systematic review, and, if applicable, } \\
\text { included in the meta-analysisf). }\end{array}$ & $\mathrm{n} / \mathrm{a}$ & \\
\hline $\begin{array}{l}\text { Data collection } \\
\text { process }\end{array}$ & 10 & 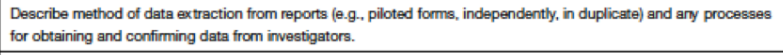 & $488-89$ & \\
\hline Data nems & 11 & \begin{tabular}{|l} 
List and define all variables forwhich data were sought (e.g., PICOS, funding sources) and ary assumptions and \\
simplifications made.
\end{tabular} & $490-93$ & \\
\hline $\begin{array}{l}\text { Risk of bias in } \\
\text { individual studies }\end{array}$ & 12 & $\begin{array}{l}\text { Describe methods used for assessing risk of bias of individual studies (including specification of whether this was } \\
\text { done at the study or outcome level). and how this information is to be used in any data anthesis. }\end{array}$ & $5 / 255-138$ & \\
\hline $\begin{array}{l}\text { Summary } \\
\text { meesures }\end{array}$ & 13 & State the principal summary measures (e.g., risk ratio, difference in means). & $45 / 106-123$ & \\
\hline $\begin{array}{l}\text { Synthesis of } \\
\text { results }\end{array}$ & 14 & $\begin{array}{l}\text { Describe the methods of handling data and combining results of studies, if done, including messures of consistency } \\
\text { (e.g. f) for ach meta-analysis. }\end{array}$ & $45 / 106-123$ & \\
\hline $\begin{array}{l}\text { Risk of bias across } \\
\text { studies }\end{array}$ & 15 & $\begin{array}{l}\text { Specifify ary assessment of nisk of bias that may affect the curnulative evidences (e.g. publication bias, selective } \\
\text { repporting within studias). }\end{array}$ & $5 / 25-138$ & \\
\hline $\begin{array}{l}\text { Additional } \\
\text { analyses }\end{array}$ & 16 & $\begin{array}{l}\text { Describe methods of additional analyses (e.g., sensitivity or subgroup analyses, meta regression), if done, indicating } \\
\text { which were pre-specified. }\end{array}$ & 5/18-123 & \\
\hline \multicolumn{5}{|l|}{ RESULTS } \\
\hline Study selection & 47 & $\begin{array}{l}\text { Give numbers of studies screened, assessed for eligbility, and included in the review, with reasons for exclusions at } \\
\text { each stage, ideally with a flow diagram. }\end{array}$ & Supplemental Figure 1 & \\
\hline $\begin{array}{l}\text { Study } \\
\text { characteristics }\end{array}$ & 18 & $\begin{array}{l}\text { For each study, present characteristics for which data were extracted (e.g, study sze日, PICOS, follow-up period) and } \\
\text { provide the citations. }\end{array}$ & 6144-161 & \\
\hline $\begin{array}{l}\text { Risk of bias within } \\
\text { studies }\end{array}$ & 19 & Present data on risk of biss of each study and, if avaliable, ary outtoome level assessment (see ittem 12). & 01163-166 & \\
\hline $\begin{array}{l}\text { Results of } \\
\text { individual studies }\end{array}$ & 20 & $\begin{array}{l}\text { For all outcomes considered (benefits or harms). present, for each study: (a) simple summary data for each } \\
\text { intervention group (b) effect restimates and confidences intervals, ideally with a forest plot. }\end{array}$ & 6-7/168-196 & \\
\hline $\begin{array}{l}\text { Synthesis of } \\
\text { results }\end{array}$ & 21 & Present results of each metta-analysis done, including confidence intervals and measures of consistenoy. & 6-71168-196 & \\
\hline $\begin{array}{l}\text { Risk of bias across } \\
\text { studies }\end{array}$ & 22 & Present results of arry assessment of risk of bias across studies (see them 15). & 61163-160 & \\
\hline Additional analysis & 23 & Give results of additional analyses, if done (e.g., sensitivity or subgroup analysses, meta-regression [see them 16]). & 7-8/198-215 & \\
\hline \multicolumn{5}{|l|}{ DISCUSSION } \\
\hline $\begin{array}{l}\text { Summary of } \\
\text { evidence }\end{array}$ & 24 & $\begin{array}{l}\text { Summarzize the main findings including the strength of evidence for each main outcome; consider their relevance to } \\
\text { key groups (e.g., haelthcrese providers, users, and policy makerss). }\end{array}$ & 9-10217-259 & \\
\hline Limitations & 25 & $\begin{array}{l}\text { Discuss limitations at study and outcome level (e.g., risk of bias), and at review-level (e.g., incomplete retrieval of } \\
\text { identified research, reporting biass). }\end{array}$ & 102261-1269 & \\
\hline Conclusions & 26 & Provide a ganeral interpretation of the results in the context of other evidence, and implications for future research. & $10 / 271-276$ & \\
\hline \multicolumn{5}{|l|}{ FUNDING } \\
\hline Funding & 27 & $\begin{array}{l}\text { Describe sources of funding for the systematic review and other support (e.g., supply of datal; role of funders for the } \\
\text { systematic review. }\end{array}$ & $11 / 278-279$ & \\
\hline
\end{tabular}

From: Moher D, Liberati A, Tetzlaff J, Altman DG, The PRISMA Group (2009). Preferred Reporting Items for Systematic Reviews and Meta-Analyses: The PRISMA Statement. PLoS Med 6(7): e1000097. doi:10.1371/journal.pmed1000097

For more information, visit: uwrw.prisma-statementorg

Figure S1 PRISMA Checklist.

(c) Annals of Cardiothoracic Surgery. All rights reserved. 
Table S1 Quality assessment of studies using the Newcastle-Ottawa Scale

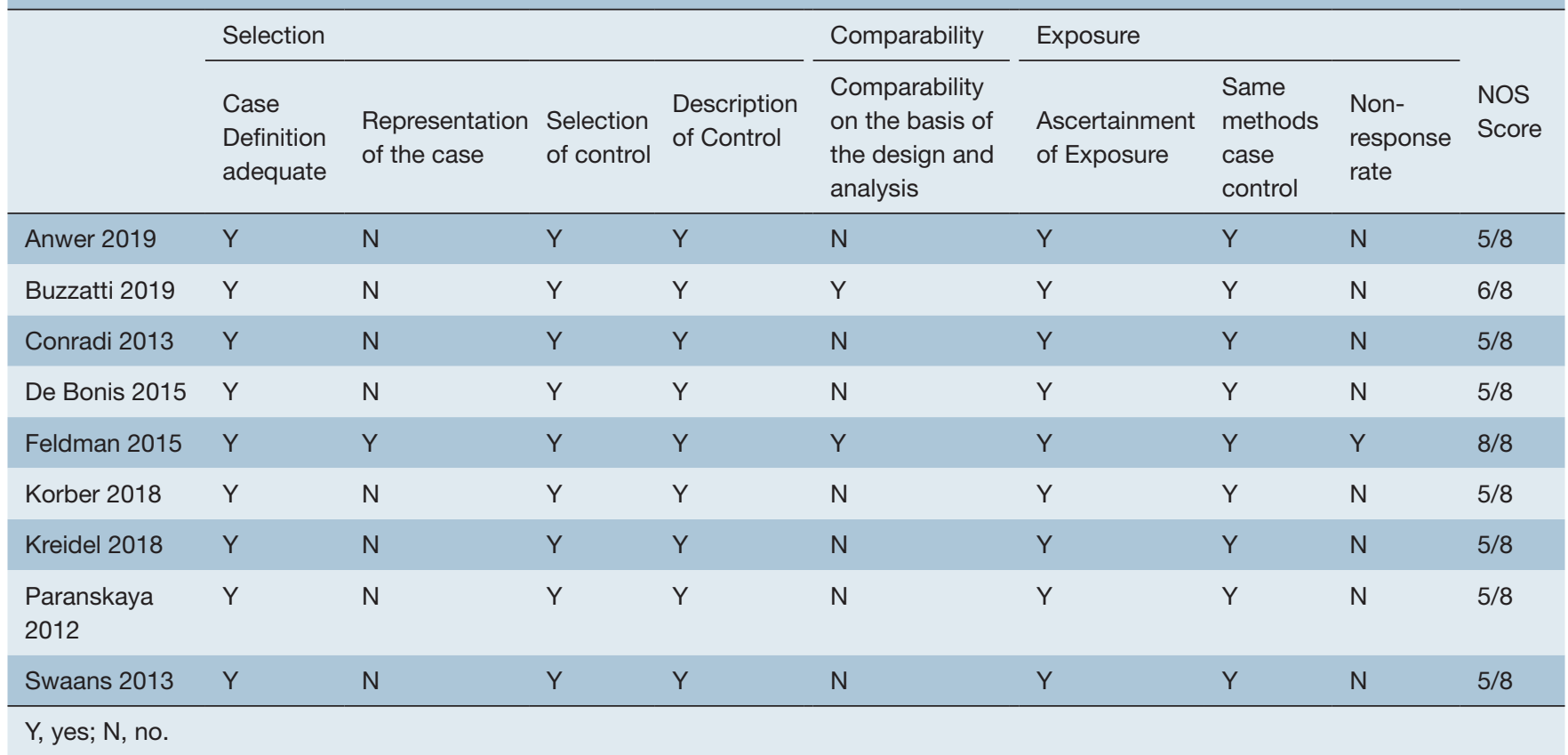

\begin{tabular}{|c|c|c|c|c|c|}
\hline \multirow{2}{*}{ Outcomes } & \multicolumn{2}{|c|}{ Anticipated absolute effects* $(95 \% \mathrm{CI})$} & \multirow{2}{*}{$\begin{array}{l}\text { Relative } \\
\text { effect } \\
(95 \% \text { CI })\end{array}$} & \multirow{2}{*}{$\begin{array}{l}\text { № of participants } \\
\text { (studies) }\end{array}$} & \multirow{2}{*}{$\begin{array}{c}\text { Certainty of the evidence } \\
\text { (GRADE) }\end{array}$} \\
\hline & Risk with MVR & $\begin{array}{l}\text { Risk with } \\
\text { MitraClip }\end{array}$ & & & \\
\hline 30-day Mortality & 15 per 1,000 & $\begin{array}{l}2 \text { per } \mathbf{1 , 0 0 0} \\
(-9 \text { to } 14)\end{array}$ & $\begin{array}{c}\text { OR 0.16 } \\
(-0.60 \text { to } \\
0.93)\end{array}$ & $\begin{array}{c}1435 \\
\text { (8 observational } \\
\text { studies) }\end{array}$ & $\begin{array}{c}\oplus \oplus \oplus \bigcirc \\
\text { MODERATE }\end{array}$ \\
\hline 1-year Mortality & 120 per 1,000 & $\begin{array}{l}83 \text { per } 1,000 \\
(32 \text { to } 127)\end{array}$ & $\begin{array}{c}\text { OR 0.66 } \\
(0.24 \text { to } \\
1.07)\end{array}$ & $\begin{array}{c}804 \\
\text { (5 observational } \\
\text { studies) }\end{array}$ & $\begin{array}{c}\oplus \oplus \bigcirc \bigcirc \\
\text { LOW }\end{array}$ \\
\hline 5 -year Mortality & 496 per 1,000 & $\begin{array}{l}\mathbf{3 4 7} \text { per } \mathbf{1 , 0 0 0} \\
(-1,000 \text { to } 662)\end{array}$ & $\begin{array}{c}\text { OR } 0.54 \\
(-0.92 \text { to } \\
1.99)\end{array}$ & $\begin{array}{c}756 \\
\text { (3 observational } \\
\text { studies) }\end{array}$ & $\begin{array}{c}\oplus \oplus \bigcirc \bigcirc \\
\text { LOW }\end{array}$ \\
\hline $\begin{array}{c}\text { Mitral } \\
\text { Regurgitation }> \\
3+/ 4 \text { at } 30 \text { days }\end{array}$ & 10 per 1,000 & $\begin{array}{l}16 \text { per } \mathbf{1 , 0 0 0} \\
(6 \text { to } 25)\end{array}$ & $\begin{array}{l}\text { OR 1.62 } \\
(0.61 \text { to } \\
2.62)\end{array}$ & $\begin{array}{c}685 \\
\text { (6 observational } \\
\text { studies) }\end{array}$ & $\begin{array}{c}\oplus \oplus \bigcirc \bigcirc \\
\text { LOW }\end{array}$ \\
\hline $\begin{array}{c}\text { Mitral } \\
\text { Regurgitation }> \\
3+/ 4 \text { at } 5 \text { years }\end{array}$ & 40 per 1,000 & $\begin{array}{l}90 \text { per } 1,000 \\
(68 \text { to } 112)\end{array}$ & $\begin{array}{c}\text { OR 2.39 } \\
(1.76 \text { to } \\
3.03)\end{array}$ & $\begin{array}{c}684 \\
\text { (3 observational } \\
\text { studies) }\end{array}$ & $\begin{array}{c}\oplus \oplus \oplus \bigcirc \\
\text { MODERATE }\end{array}$ \\
\hline $\begin{array}{l}\text { Length of stay } \\
\text { assessed with: } \\
\text { hospitalization days }\end{array}$ & $\begin{array}{l}\text { The mean length of } \\
\text { stay was 8.4 Days }\end{array}$ & $\begin{array}{l}\text { 3.9 Days lower } \\
\text { (6.86 lower to } 0.93 \\
\text { lower) }\end{array}$ & - & $\begin{array}{c}1177 \\
\text { (7 observational } \\
\text { studies) }\end{array}$ & $\begin{array}{c}\oplus \oplus \oplus \bigcirc \\
\text { MODERATE }\end{array}$ \\
\hline Acute kidney injury & 267 per 1,000 & $\begin{array}{l}\mathbf{- 1 0 9} \text { per } \mathbf{1 , 0 0 0} \\
(-1,000 \text { to } 267)\end{array}$ & $\begin{array}{c}\text { OR }-\mathbf{0 . 2 7} \\
(-1.54 \text { to } \\
1.00)\end{array}$ & $\begin{array}{c}985 \\
\text { (5 observational } \\
\text { studies) }\end{array}$ & $\begin{array}{c}\oplus \oplus \oplus \bigcirc \\
\text { MODERATE }\end{array}$ \\
\hline
\end{tabular}

Figure S2 Certainty of the body of evidence assessment using the grading of recommendations assessment, development, and evaluation (GRADE) framework. 

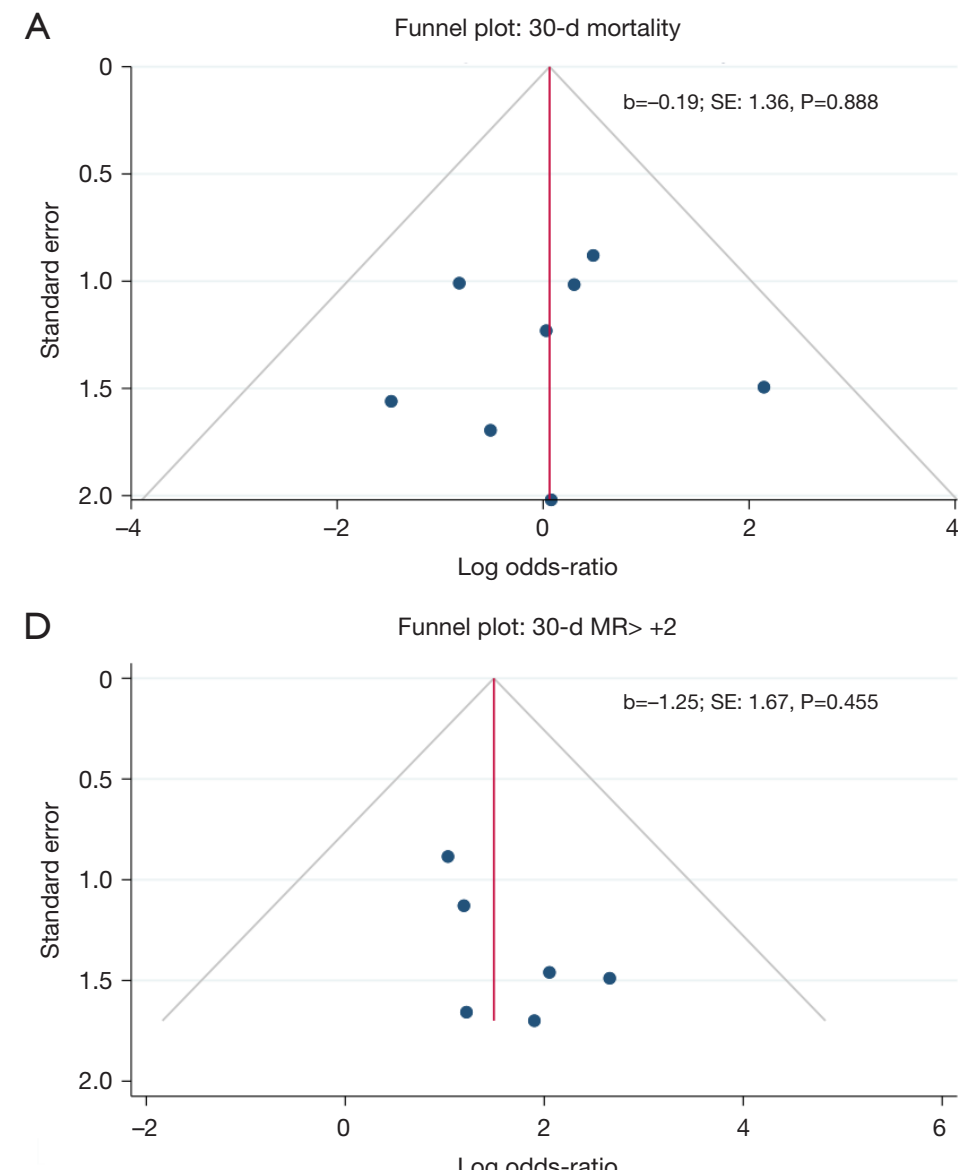

B

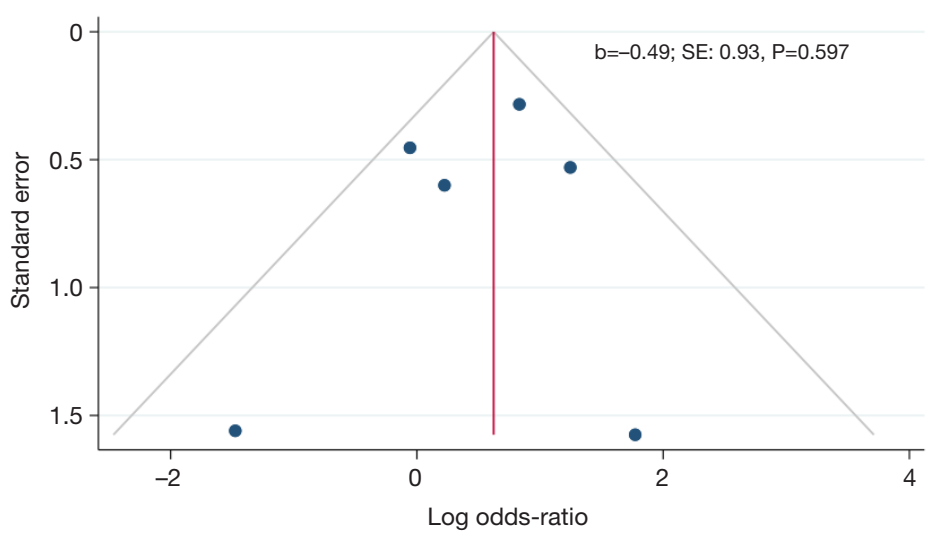

$E$

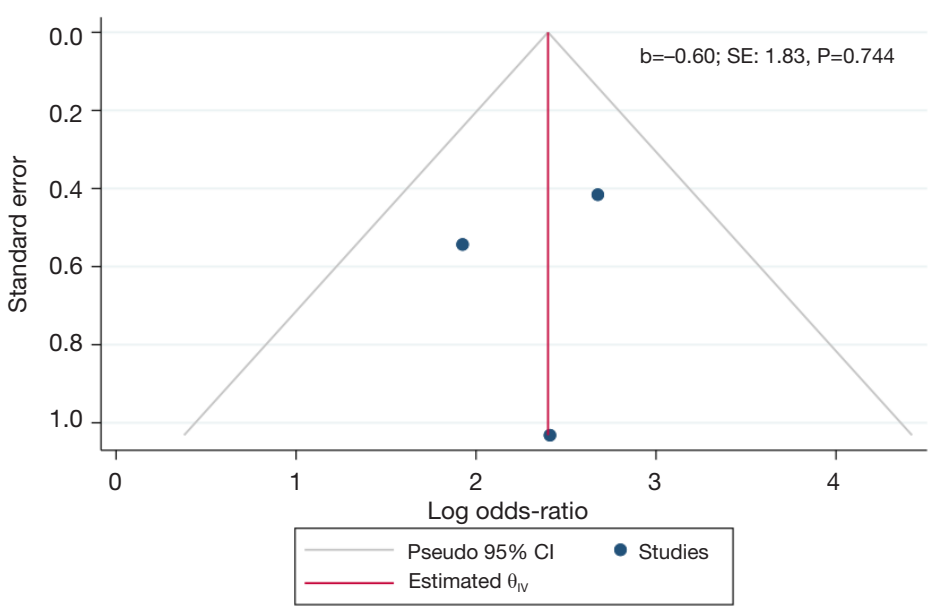

C

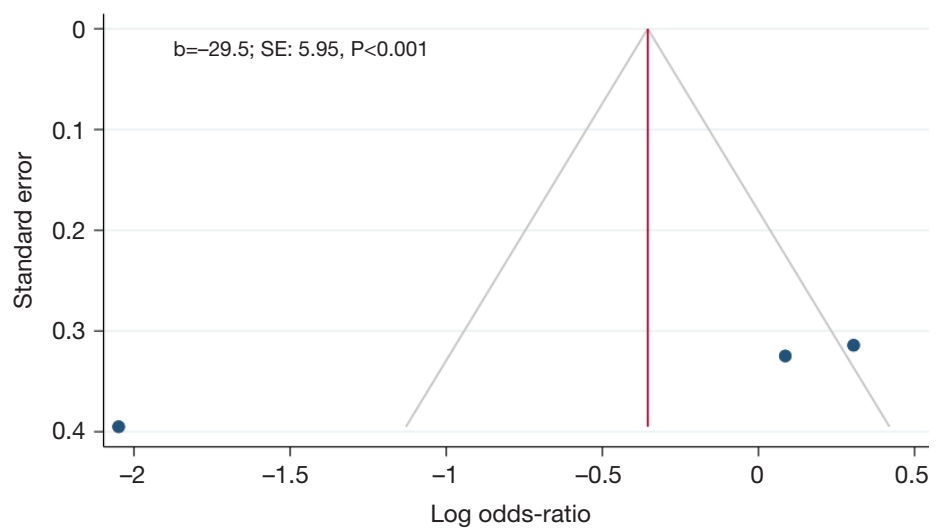

$\mathrm{F}$

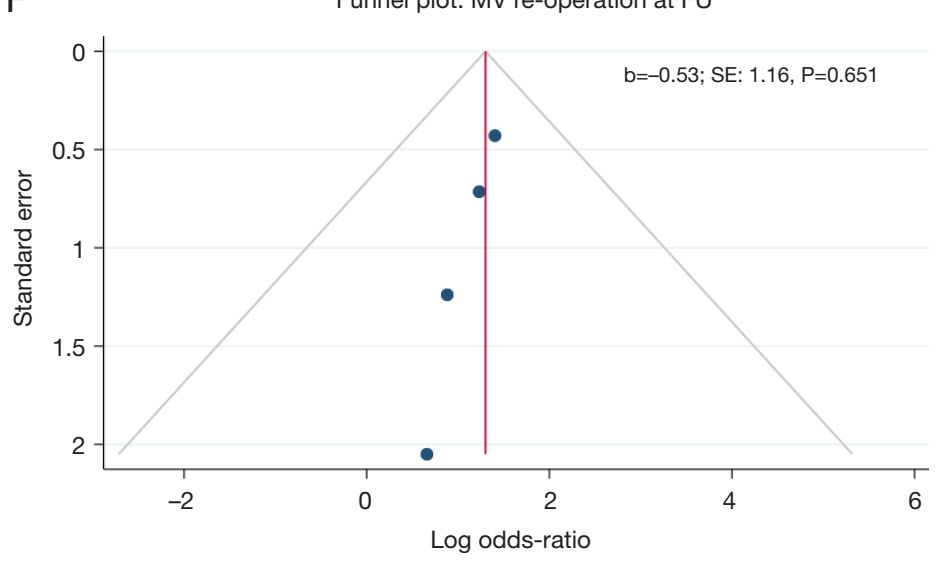

Figure S3 Funnel plot used to evaluate for publication bias.

Table S2 Moderators of outcomes derived from metaregression analysis

\begin{tabular}{|c|c|c|c|c|c|c|c|c|c|c|c|c|c|c|c|c|c|c|}
\hline \multirow{2}{*}{ Moderator } & \multicolumn{3}{|c|}{ 30-day Mortality } & \multicolumn{3}{|c|}{ 1-year Mortality } & \multicolumn{3}{|c|}{ 5-year Mortality } & \multicolumn{3}{|c|}{$\mathrm{MR}>+2$ at Discharge } & \multicolumn{3}{|c|}{$\mathrm{MR}>+2$ at 5 years } & \multicolumn{3}{|c|}{ MV Reoperation at FU } \\
\hline & Coefficient & $95 \% \mathrm{Cl}$ & $P$ value & Coefficient & $95 \% \mathrm{Cl}$ & $P$ value & Coefficient & $95 \% \mathrm{Cl}$ & $P$ value & Coefficient & $95 \% \mathrm{Cl}$ & $P$ value & Coefficient & $95 \% \mathrm{Cl}$ & $P$ value & Coefficient & $95 \% \mathrm{Cl}$ & $P$ value \\
\hline Age & 0.04 & $-0.15,0.22$ & 0.679 & 0.05 & $-0.07,0.16$ & 0.421 & -0.16 & $-0.32,-0.01$ & 0.038 & -0.04 & $-0.37,0.30$ & 0.831 & 0.04 & $-0.04,0.13$ & 0.304 & -0.03 & $-0.27,0.21$ & 0.786 \\
\hline Male Gender & -3.25 & $-14.04,7.53$ & 0.555 & 0.02 & $-7.82,7.86$ & 0.997 & 30.87 & $18.64,43.11$ & 0.000 & -0.28 & $-12.62,12.1$ & 0.964 & -3.89 & $-10.84,3.06$ & 0.272 & -1.85 & $-12.64,8.92$ & 0.735 \\
\hline EuroSCORE & 0.03 & $-0.16,0.23$ & 0.743 & -0.1 & $-0.44,0.25$ & 0.570 & Omitted & & & -0.01 & $-0.18,0.18$ & 0.960 & Omitted & & & -0.01 & $-.030,0.27$ & 0.926 \\
\hline STS Score & -0.35 & $-1.14,0.45$ & 0.389 & 0.24 & $-0.34,0.82$ & 0.413 & Omitted & & & 0.36 & $-1.22,1.95$ & 0.654 & 0.13 & $-0.91,1.17$ & 0.811 & -0.24 & $-2.19,1.71$ & 0.806 \\
\hline Atrial Fibrillation & 1.68 & $-2.64,5.99$ & 0.446 & 0.35 & $-2.69,3.39$ & 0.823 & 6.01 & $-3.04,15.06$ & 0.193 & -1.46 & $-6.46,3.53$ & 0.566 & -4.61 & $-16.02,6.81$ & 0.429 & -0.27 & $-3.95,3.40$ & 0.883 \\
\hline Diabetes Mellitus & 2.76 & $-5.32,10.85$ & 0.503 & 3.85 & $-1.05,8.75$ & 0.124 & -1.59 & $-9.26,6.07$ & 0.684 & -5.20 & $-21.04,10.64$ & 0.520 & Omitted & & & -0.62 & $-5.77,4.53$ & 0.813 \\
\hline COPD & 0.15 & $-2.52,2.82$ & 0.912 & 0.72 & $-0.89,2.34$ & 0.380 & 13.31 & $-14.06,40.69$ & 0.341 & -0.59 & $-3.45,2.27$ & 0.686 & -6.14 & $-124.1,112.1$ & 0.919 & -0.19 & $-2.12,1.73$ & 0.848 \\
\hline CKD & -1.23 & $-7.78,5.32$ & 0.713 & 27.44 & $-41.34,96.22$ & 0.434 & Omitted & & & 1.25 & $-5.83,8.32$ & 0.730 & Omitted & & & Omitted & & \\
\hline Hypertension & 55.02 & $-78.1,188.1$ & 0.418 & 2.17 & $-3.89,8.23$ & 0.483 & 0.95 & $-3.13,5.03$ & 0.647 & -3.56 & $-17.86,10.74$ & 0.625 & Omitted & & & Omitted & & \\
\hline
\end{tabular}


A

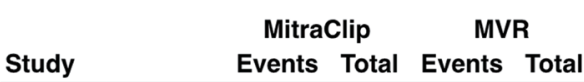

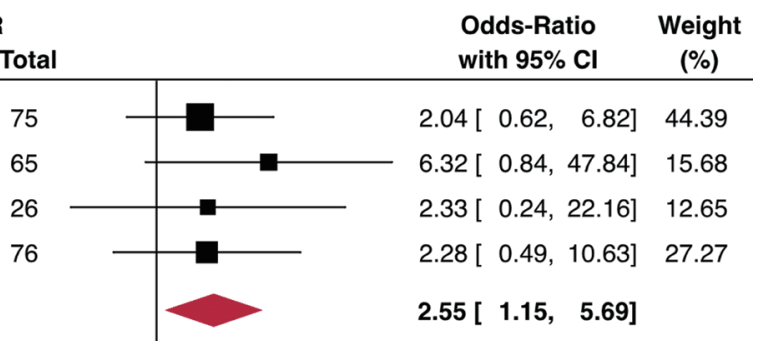

Heterogeneity: $\mathrm{T}^{2}=0.00, \mathrm{I}^{2}=0.00 \%, \mathrm{H}^{2}=1.00$

Test of $\theta=0: z=2.30, p=0.02$

$\begin{array}{llll}\text { Anwer 2019 } & 4 & 56 & 2 \\ \text { de Bonis 2015 } & 5 & 55 & 0 \\ \text { Paranskaya 2012 } & 1 & 24 & 0 \\ \text { Conradi 2013 } & 4 & 95 & 1\end{array}$

Overall

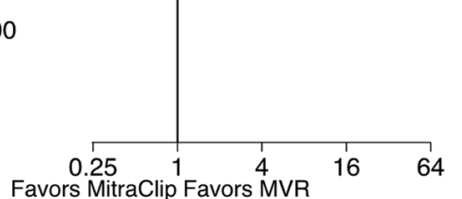

B

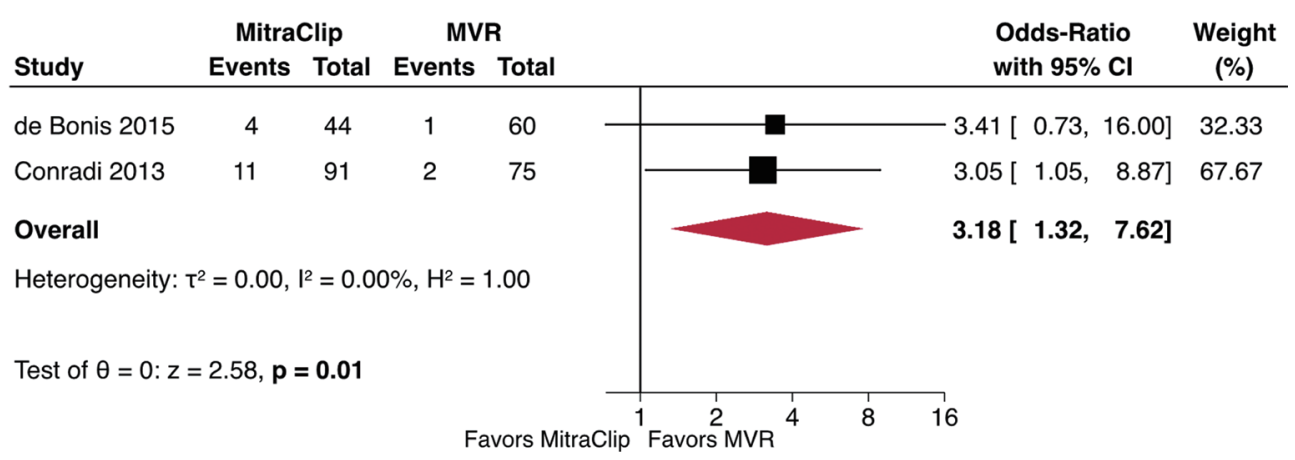

Figure S4 Forest plot of the comparison between MitraClip and MV repair for mitral moderate/severe regurgitation at discharge (A) and at 1 year post-operatively (B). 